\title{
Dairy farms testing positive for Mycobacterium avium ssp. paratuberculosis have poorer hygiene practices and are less cautious when purchasing cattle than test-negative herds
}

\author{
R. Wolf, ${ }^{*} \dagger^{1}$ H. W. Barkema, $\dagger$ J. De Buck, $\dagger$ and K. Orsel† \\ *Amt der Steiermärkischen Landesregierung, 8010 Graz, Austria \\ †Department of Production Animal Health, University of Calgary, Calgary, AB, T2N 4N1, Canada
}

\begin{abstract}
Mycobacterium avium ssp. paratuberculosis (MAP), the causative agent of Johne's disease, is present on most dairy farms in Alberta, causing economic losses and presenting a potential public health concern. The objective of this cross-sectional study was to identify risk factors for Alberta dairy herds being MAP-positive based on environmental samples (ES). Risk assessments were conducted and ES were collected on 354 Alberta dairy farms ( $62 \%$ of eligible producers) voluntarily participating in the Alberta Johne's Disease Initiative. In univariate logistic regression, risk factors addressing animal and pen hygiene, as well as the use of feeding equipment to remove manure and manure application on pastures, were all associated with the number of positive ES. Furthermore, based on factor analysis, risk factors were clustered and could be summarized as 4 independent factors: (1) animal, pen, and feeder contamination; (2) shared equipment and pasture contamination; (3) calf diet; and (4) cattle purchase. Using these factor scores as independent variables in multivariate logistic regression models, a 1-unit increase in animal, pen, and feeder contamination resulted in 1.31 times higher odds of having at least 1 positive ES. Furthermore, a 1-unit increase in cattle purchase also resulted in 1.31 times the odds of having at least 1 positive ES. Finally, a 100-cow increase in herd size resulted in an odds ratio of 2.1 for having at least 1 positive ES. In conclusion, cleanliness of animals, pens, and feeders, as well as cattle purchase practices, affected risk of herd infection with MAP. Therefore, improvements in those management practices should be the focus of effective tools to control MAP on dairy farms.
\end{abstract}

Key words: paratuberculosis, Mycobacterium avium ssp. paratuberculosis, risk factor, cattle, environmental samples

Received October 2, 2015.

Accepted February 13, 2016.

${ }^{1}$ Corresponding author: robert.wolf@stmk.gv.at

\section{INTRODUCTION}

Mycobacterium avium ssp. paratuberculosis (MAP) causes Johne's disease (JD), a chronic progressive enteritis that inevitably leads to culling or death of the animal (Fecteau and Whitlock, 2010). Unfortunately, MAP is common in countries with a modern dairy industry, with $>70 \%$ of western Canadian dairy farms regarded as being infected (Barkema et al., 2010b; Wolf et al., 2014a). The high herd prevalence and associated production losses, as well as the potentially zoonotic nature of MAP, have led to implementation of control programs in many countries (Barkema et al., 2010a; Ott et al., 1999). Because diagnosis of MAP infection is challenging (Collins et al., 2006), these programs focus on disrupting pathogen transmission. As cows are responsible for most MAP contamination on a farm and calves are most susceptible (Windsor and Whittington, 2010; Sweeney, 2011), interruption of direct or indirect cow-calf contact has been the focus of most programs (McKenna et al., 2006). This is supported by several studies identifying risk factors related to direct or indirect cow-to-calf contact, including feeding pooled milk or colostrum (Nielsen et al., 2008), poor calving pen hygiene (Ansari-Lari et al., 2009), and group calving pens (Wells and Wagner, 2000; Pithua et al., 2013). In addition, factors related to prolonged survival of MAP in the environment (e.g., application of slurry on cropland) were also identified (Johnson-Ifearulundu and Kaneene, 1999; Fecteau et al., 2010). Nevertheless, despite prior knowledge on risk factors for MAP infection, no effective control strategy exists to prevent herds from becoming infected and to reduce the withinherd prevalence on infected herds. Furthermore, results of previous studies need to be confirmed and effective management strategies might differ between different dairy populations. The Alberta Johne's Disease Initiative (AJDI; Wolf et al., 2014b) assessed a variety of management practices and hygiene measures for cattle in all age groups. With a participation rate of $>60 \%$ among eligible producers, the AJDI was one of the Canadian MAP control programs with the highest par- 
ticipation. The objective of our study was to identify risk factors for Alberta dairy herds being MAP-culture positive based on environmental samples.

\section{MATERIALS AND METHODS}

\section{Herd Selection and Data Collection}

The study population for this cross-sectional study was composed of herds participating in the AJDI, a voluntary JD control program available for all dairy producers in the province of Alberta, Canada (Wolf et al., 2014b). All 571 dairy producers that delivered milk to a processing plant were eligible to join the project (Canadian Dairy Information Centre, 2014). Data used in our study were collected between November 2010 and April 2014 by 91 trained herd veterinarians, each of whom had completed a 5 -h workshop on conducting AJDI risk assessments (RA) and collection of environmental samples (ES). Because farms could join or leave the project at any time, the number of herd visits varied among farms. Participating farms were visited annually. During each visit, 6 ES were collected at 3 different sites on a farm (Wolf et al., 2014a): (1) lactating cow pens; (2) dry, sick, or calving pens; and (3) manure storage areas. Each ES had to contain at least 4 subsamples that were mixed in a resealable bag. Sample collectors were asked to store ES at $4^{\circ} \mathrm{C}$ for a maximum of $24 \mathrm{~h}$ and send them to University of Calgary using express mail, where they were stored at $4^{\circ} \mathrm{C}$ for a maximum of $7 \mathrm{~d}$. All ES were processed using a Trek ESP culture protocol (Trek Diagnostic Systems, Oakwood Village, OH), with subsequent IS900 PCR confirmation (Vary et al., 1990) and the case definition was the dichotomous IS900 PCR result (Forde et al., 2013).

During the same visit, an RA was conducted containing 34 questions [questions 1-34 in Appendix Table A1]. The first 4 questions dealt with herd characteristics and information on participation in previous JD control programs. The remaining 30 questions were the actual risk factors derived from web resources and following scientific evidence (USDA, 2003; Doré et al., 2012; Elliott et al., 2015), which were divided into 6 sections: general, preweaned heifers, weaned to first-calving heifers, calving area, dry cows, and lactating cows. Each section contained questions regarding potential risk factors for fecal-oral transmission of MAP between individuals and for MAP introduction. All questions were closed questions and participants were asked to choose 1 answer per question. Questions on management were answered by the participating farmers. However, the veterinarians recorded their own observations for questions regarding cleanliness. Veterinarians were blinded throughout data collection, as ES results were not available when the RA was conducted.

\section{Statistical Analyses}

Statistical analyses were conducted using STATA version 11 (Statacorp, College Station, TX). Data from the first herd visit of each participant were included. Potential predictors were risk factors assessed within the RA (Appendix Table A1). A causal diagram was used to image potential associations before analysis (Greenland et al., 1999). It was consequently hypothesized that certain risk factors (trade, cattle shows) were associated with MAP introduction into a herd, whereas others (cleanliness, calving management) were associated with within-herd transmission (Figure 1). It was further concluded that within-herd transmission could only occur in MAP-infected herds and influenced MAP within-herd prevalence, which further affected the number of positive ES. The number of clinical cases and test-positive animals was a collider on the causal pathway and was therefore excluded from any further analysis (Greenland et al., 1999).

Two approaches were used for data analysis, following recommendations for dealing with large numbers of independent variables (Dohoo et al., 1997): (1) univariate analysis to assess crude associations between the outcome and risk factors; and (2) multivariate analysis combined with factor analysis to adjust for multicollinearity in the data set.

Univariate Analysis. Logistic regression models were built with 2 different outcomes, categorized as follows: (1) 0 positive ES versus $\geq 1$ positive ES; and (2) 0 to 3 positive ES versus 4 to 6 positive ES. This outcome categorization was performed to acknowledge the association between MAP within-herd prevalence and the number of positive ES (Lavers et al., 2013), with outcome 1 estimating the odds for herds being infected versus noninfected, and outcome 2 estimating the odds for herds with high within-herd MAP prevalence versus herds with low within-herd MAP prevalence or being uninfected. Separate models were built for each of the risk factors included as categorical predictors. A $P$ value $<0.05$ overall or for at least one of the categories of a variable was considered significant.

Multivariate Analysis. To avoid multicollinearity, the independent variable matrix was summarized using factor analysis. In addition to the RA questions (5-34, except 6, Appendix Table A1), herd size and housing type were included. The Kaiser-Meyer-Olkin (KMO) measure of sampling adequacy was used to assess overall suitability of the data set, as well as suitability of variables to be included in factor analysis (Dziuban and Shirkey, 1974). A KMO value $>0.70$ was interpreted as 


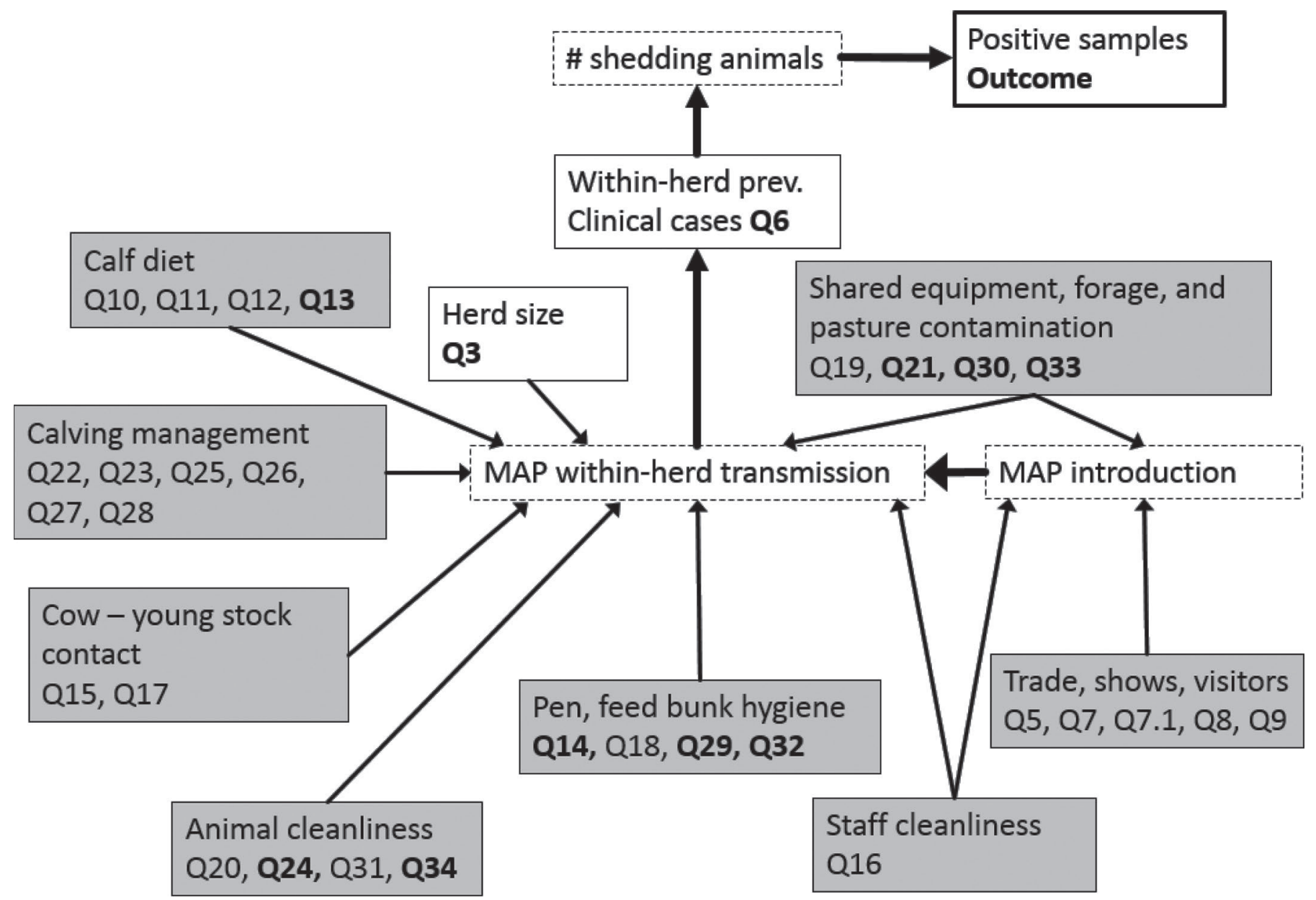

Figure 1. Causal diagram illustrating associations between risk factors assessed with questions (Q; see Appendix Table A1) as part of the Alberta Johne's Disease Initiative (AJDI) risk assessment and the number of Mycobacterium avium ssp. paratuberculosis-positive environmental samples. Dashed boxes represent factors influencing the association, but not assessed in the AJDI. Risk factors associated with the number of positive environmental samples using univariate logistic regression $(P<0.05)$ are in bold.

medium fit of the data. Variables with a KMO $<0.50$ (unacceptable fit) were excluded from factor analysis. After determining variables to be included in the analysis, the factor analysis was rerun and factors with an Eigenvalue $>1.0$ were retained. Factor loadings $>0.4$ after varimax rotation were used to describe the factors (Sieber et al., 1987).

Predicted factor scores were used as independent variables in 2 logistic regression models. The analysis used the same outcomes as univariate analysis ( 0 positive ES vs. $\geq 1$ positive ES and $<4$ positive ES vs. $>3$ positive ES). The use of separate models instead of a single ordinal logistic regression model was necessary because a significant Brant test in preliminary analysis suggested violation of the proportional odds assumption. A backward elimination procedure was used to obtain the final model. Any variables excluded from the factor analysis because $\mathrm{KMO}<0.50$ were considered additional predictors in separate models. A $P<0.05$ was interpreted as a significant association between predictor and outcome, whereas a $P$-value between 0.05 and 0.10 was interpreted as a trend. Therefore, all variables with $P<0.10$ were included in the final model.

\section{RESULTS}

A total of 370 herds participated in the AJDI ( $62 \%$ of Alberta dairy farms). Sixteen farms submitted only ES and no RA and were therefore excluded from the analysis. Furthermore, 2 farms submitted incomplete RA because all cattle in certain age groups were housed on other farms; therefore, these 2 farms were excluded from univariate analysis of questions with missing data and from factor analysis. A total of 225 (64\%) of the remaining 354 farms with RA and ES that had only MAP-negative ES, 80 (23\%) had 1 to 3 positive sam- 
ples, and 49 (14\%) had 4 to 6 positive samples. Mean herd size was 139 adult cows (range $=40$ to 680 ). The majority $(87 \%)$ of herds were in freestall barns, whereas 6 and $7 \%$ of herds were housed in loose housing and tiestalls, respectively.

\section{Univariate Analysis}

Of the 30 risk factors analyzed in univariate logistic regression, 9 were associated with the number of positive ES, with mostly similar results for the 2 outcomes.
All 9 management practices were associated with manure contamination in various areas of a farm: manure contamination of feeding equipment, poor cleanliness of heifers and cows, and application of manure on pastures and crop land used the same year for production of cattle feed (Table 1 and Figure 1).

\section{Multivariate Analysis}

Herd size, type of lactating cow housing, and attendance at cattle shows (Q8) had KMO values $<0.5$

Table 1. Risk factors associated with number of Mycobacterium avium ssp. paratuberculosis positive environmental samples (ES) on dairy farms, based on univariate logistic regression $(P<0.05)$

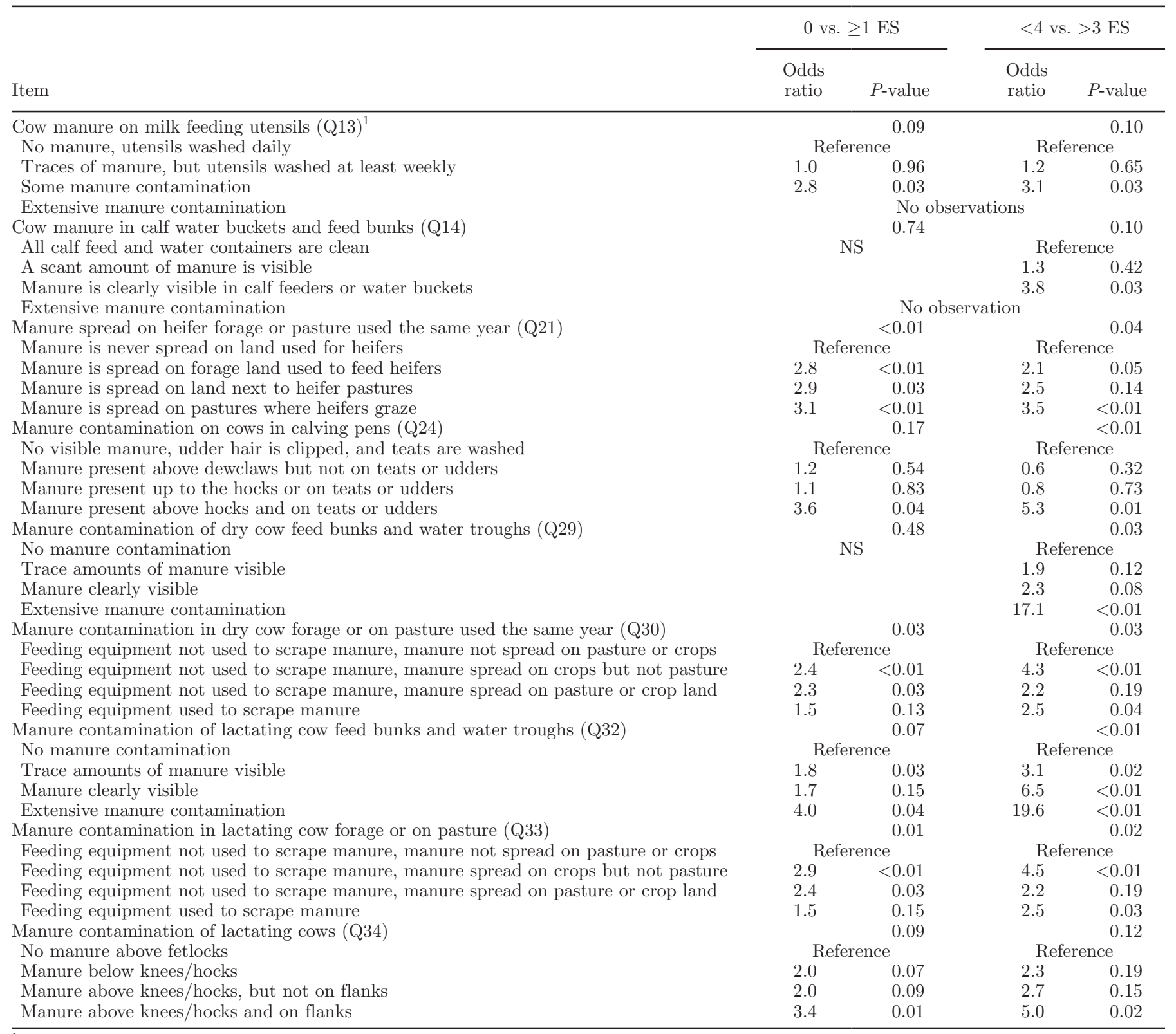

${ }^{1}$ Question number in Risk Assessment (Appendix Table A1). 
Table 2. Factor loadings on factors summarizing a risk assessment used as part of a Johne's disease control program on dairy farms (factor loadings $>0.40$ are marked in bold)

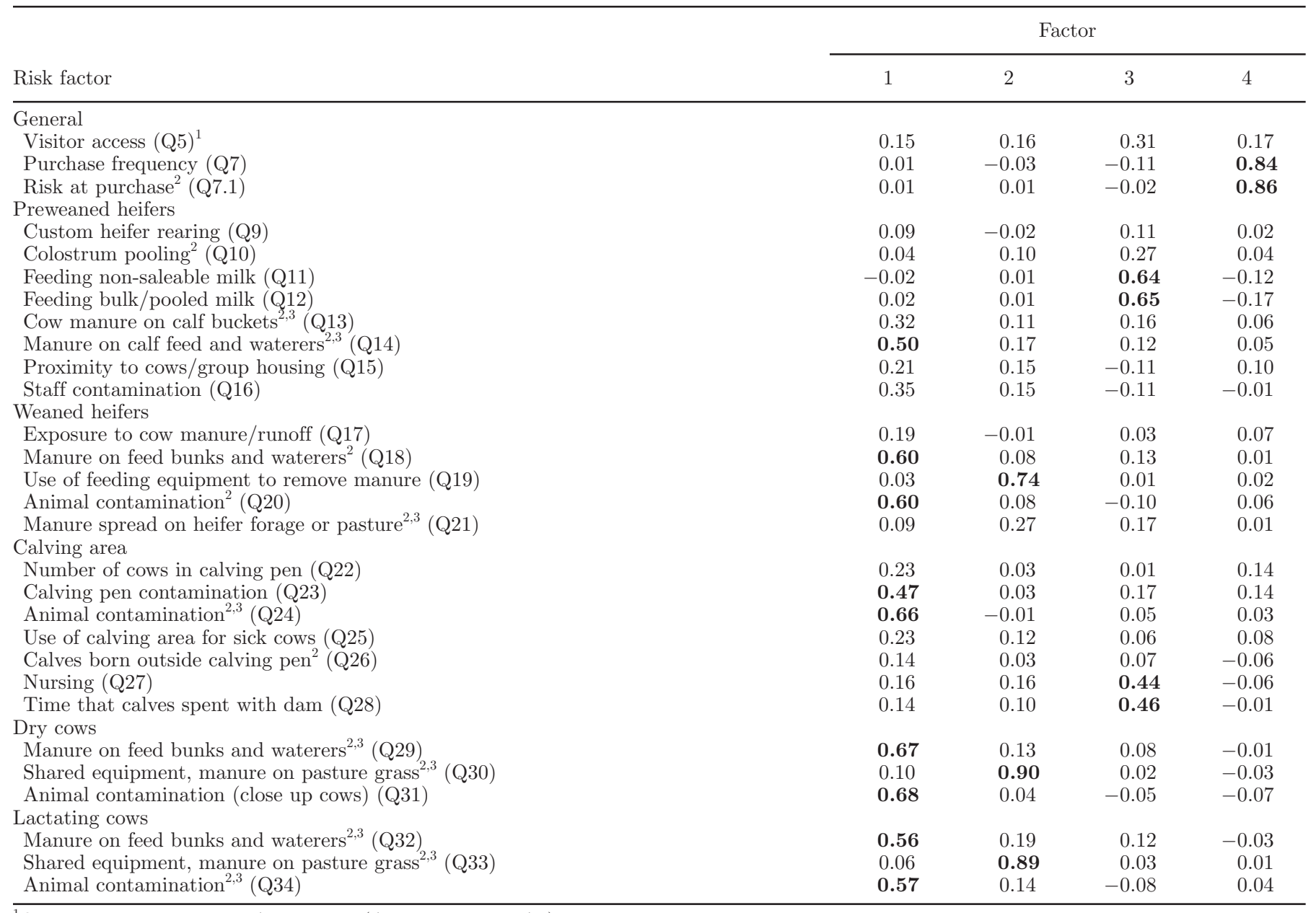

${ }^{1}$ Question number in Risk Assessment (Appendix Table A1).

${ }^{2}$ Associated with number of positive environmental samples in $\chi^{2}$ test $(P<0.20)$.

${ }^{3}$ Associated with number of positive environmental samples in univariate logistic regression $(P<0.05)$.

and were therefore excluded from factor analysis. The other risk factors were summarized with 4 factors that had an Eigenvalue $>1$. The overall KMO value was 0.75 , consistent with medium fit of the data, and the 4 factors accounted for $86 \%$ of the variance in the data. Factor 1 had factor loadings $>0.4$ for manure contamination of water troughs and feed bunks in calf, heifer, dry cow, and lactating cow pens, respectively (Table 2). Factor 1 was also associated with manure contamination of cows and heifers and with calving pen contamination; therefore, it was named animal, pen, and feeder contamination. Factor 2 (shared equipment, pasture contamination) had factor loadings $>0.4$ for the use of feeding equipment to remove manure, and with application of manure on pasture and crop land used by cows in the same year. Factor 3 (calf diet) had factor loadings $>0.4$ for feeding of nonsaleable milk and bulk milk to calves, as well as allowing calves to nurse. Factor 4 (cattle purchase) had factor loadings $>0.4$ for high frequency of cattle purchases and a low level of precaution during purchase.

In the final logistic regression, a 1-unit increase in factor 1 (animal, pen, and feeder contamination) resulted in 1.31 times higher odds of having $\geq 1$ positive ES. A 1-unit increase in factor 4 (cattle purchase) also resulted in 1.31 times higher odds of having $\geq 1$ positive ES. Herds with an increased score in factor 2 (shared equipment, pasture contamination) tended to have a higher odds of having $>3$ positive ES $(P=0.096)$. A 100 -cow increase in herd size resulted in an odds ratio of 2.1 for being above the cut-off $(\geq 1$ or $>3$ positive ES) in both models. Lactating cow housing, attendance 
Table 3. Final logistic regression model on the association between number of Mycobacterium avium ssp. paratuberculosis-positive environmental samples (ES) and factor scores summarizing information of a Johne's disease risk assessment on 352 dairy farms in Alberta, Canada

\begin{tabular}{|c|c|c|c|c|c|c|}
\hline \multirow[b]{2}{*}{ Item } & \multicolumn{3}{|c|}{0 vs. $\geq 1$ positive ES } & \multicolumn{3}{|c|}{$<4$ vs. $>3$ positive ES } \\
\hline & $\begin{array}{l}\text { Odds } \\
\text { ratio }\end{array}$ & $P$-value & $95 \% \mathrm{CI}$ & Odds ratio & $P$-value & $95 \%$ CI \\
\hline Intercept $^{1}$ & -1.61 & $<0.001$ & -2.11 to -1.11 & -3.12 & $<0.001$ & -3.81 to -2.43 \\
\hline Factor 1 (Pen and animal contamination) & 1.31 & 0.034 & 1.02 to 1.68 & 1.85 & $<0.001$ & 1.31 to 2.61 \\
\hline Factor 2 (Shared equipment, pasture contamination) & \multicolumn{3}{|c|}{ Not associated } & 1.35 & 0.096 & 0.95 to 1.93 \\
\hline Factor 4 (Cattle purchase) & 1.31 & 0.050 & 1.00 to 1.72 & \multicolumn{3}{|c|}{ Not associated } \\
\hline
\end{tabular}

${ }^{1}$ Values are coefficients (log odds).

at cattle shows, as well as factor 3 (calf diet) were not significantly associated with any of the ES outcomes (Table 3).

\section{DISCUSSION}

Animal, pen, and feeder contamination with manure, cattle purchase frequency and purchase precautions, as well as the use of feeding equipment to remove manure and apply manure on forage land and pasture all increased risk for MAP-positive ES. Therefore, improvements in those management practices might be the most effective tools to control MAP on dairy farms.

Manure contamination of animals, waterers, and feed troughs, as well as calving pens (factor 1) were positively associated with the number of MAP culturepositive ES. Furthermore, there were reduced odds for ELISA-positive cattle on farms that cleaned calving pens after each use (Johnson-Ifearulundu and Kaneene, 1998), which partially confirmed our findings. The association was biologically plausible, as high levels of contamination likely increased risk of MAP ingestion in infected herds. It would obviously be important to know in which age groups these transmission events occurred, particularly because recent work provided evidence that cattle up to at least $1 \mathrm{yr}$ of age were susceptible to MAP and that exposed cattle shed MAP soon after infection (Mortier et al., 2013, 2014). However, based on the factor loadings, it was clear that individual risk factors were correlated. For example, whereas only $6 \%$ of farms with visibly clean lactating cows had severely contaminated heifers, $28 \%$ of farms with severely contaminated lactating cows had severely contaminated heifers (results not shown). Consequently, risk factors for specific age groups could not be identified, although it was noteworthy that herds with poor hygiene in pens were more likely to be MAP-positive.

In contrast to factor 1 (animal, pen, and feeder contamination), factor 4 (cattle purchase) described a risk factor for MAP introduction rather than MAP within-herd transmission. As in a previous study, herds with frequent cattle introductions and low precautions during purchase were more likely to be MAP infected (Nielsen and Toft, 2011). Considering that $\sim 18 \%$ of cattle in Alberta were estimated to be infected with MAP (Scott et al., 2006), cattle purchases were regarded as an important route for MAP introduction.

Factor 2 (shared equipment and pasture contamination) tended to be associated with the number of positive ES at a $P$-value $\sim 0.1$. This factor had high loadings on the use of the same equipment for feeding and manure removal, as well as manure application on pastures and cropland used in the same year. As many of these risk factors were associated with the outcome in univariate analysis, the factor was retained in the final model, despite a $P$-value $>0.05$. Significance was also supported by prior evidence for plausibility of this association, as MAP survives in the environment for extended intervals, making contaminated equipment and cropland use after manure application a likely risk factor (Whittington et al., 2004). In addition, in a US study, an increased risk for herds testing positive was noted if manure was spread on land where calf feed was grown (Johnson-Ifearulundu and Kaneene, 1999).

Larger herds had higher odds for being infected with MAP than smaller herds, which was previously attributed to differences in management between large and small herds, as described in several publications (Wells and Wagner, 2000; Pillars et al., 2009; Wolf et al., 2014a). It was hypothesized that large herds purchase more cattle, which would increase their risk for MAP introduction. However, herd size was excluded from the factor analysis, because KMO $<0.5$ provided no evidence for herd size-dependent risk factors. Notwithstanding, perhaps management practices that were not assessed within the AJDI were herd size-dependent and affected the number of positive ES. Potential candidates were management practices related to calf housing, as infected calves can excrete MAP (Mortier et al., 2014; Wolf et al., 2015), and calf-to-calf transmission was documented (van Roermund et al., 2007). However, contacts between infectious and susceptible 
cattle might be more frequent in large herds, resulting in increased frequency of MAP transmission. Nonetheless, more research is needed, especially because the average size of dairy herds keeps increasing (Barkema et al., 2015).

Many risk factors regarding colostrum and calving pen management were not associated with farms being ES-positive, but were biologically plausible and previously reported; however, these practices should not be neglected in MAP control. Because the present study was observational, data distribution compromised identification of some known risk factors. For example, only 9 farms raised their heifers on external rearing operations where they were mixed with young stock from other herds. Unfortunately, it was not possible to determine the association with herds being MAPinfected with this risk factor, although that could be a focus of future research.

Identified risk factors were regarded as important for control of other infectious diseases and should be included in any biosecurity program. Increased purchase volumes with low precautions also increased risk for introduction of many other infectious diseases such as infectious bovine rhinotracheitis, bovine viral diarrhea virus, or digital dermatitis (van Schaik et al., 2002). Animal and pen cleanliness also affected transmission of other pathogens. Whereas low hygiene standards in calf housing increased the incidence of diarrhea as well as bovine respiratory disease (Johnson et al., 2011), a quick and dirty management style for cows increased both bulk milk SCC and incidence of clinical mastitis (Barkema et al., 1999). Therefore, this additional importance of the identified risk factors strengthened the evidence for inclusion of these factors in biosecurity programs.

As in a previous study (Berghaus et al., 2005), some risk factors were correlated which could have been regarded as a limitation, as this lack of independence compromised our ability to identify specific risk factors for MAP infection. However, we also inferred that management decisions were not made independently, but instead followed a management strategy on a farm, which could be influenced by herd advisers as a whole to reduce disease spread.

Interobserver variability in scoring of risk factors and ES collection was not assessed in the present study, but was mitigated through observer training, as all personnel involved in data collection attended a halfday training seminar explaining standard procedures regarding sample collection and risk assessment conduction. Therefore, this was expected to have reduced the magnitude of this potential bias.

Our cross-sectional study design did not allow assessment of causation. Because exposure and environmental contamination were measured concurrently, farms could have changed their management as part of previous control efforts, but could still have had a high withinherd prevalence because management changes were not yet effective. This would have resulted in biased odds ratios and failure to identify important risk factors, or risk factors could even have appeared as protective. Fortunately, the potential for this bias appeared to be low, as the majority of farms were not involved in any MAP control programs in the past $10 \mathrm{yr}$, and none of the biologically plausible risk factors were inversely associated with the outcome. Furthermore, results could be biased through uncontrolled confounding through management practices that were not assessed within the RA. The potential for this bias should be low, because most known risk factors were assessed and the RA included questions for all age groups on farms.

Environmental samples were used to assess the outcome with a sensitivity of $\sim 70 \%$, misclassifying some low prevalence herds as negative (Wolf et al., 2014a). Because this happened independent of exposure, nondifferential misclassification caused an underestimation of the odds of MAP infection on dairy herds, suggesting that reported odds ratios were rather conservative (Dohoo et al., 2003).

We found evidence for violation of internal validity of the study, because herd prevalence and herd size were similar between AJDI participants and nonparticipants (Ritter et al., 2014). External validity was difficult to estimate, as comparable management data from other dairy populations were not available. However, findings of our study are similar to results of other studies, which provides evidence for generalizability of results to dairy cattle populations with similar production systems (USDA, 2003; Doré et al., 2012; Elliott et al., 2015).

Poor hygiene of cattle, feed, and water troughs, as well as calving pens, high purchase frequency, and low precautions during purchase, along with the use of manure equipment for feeding and spreading of manure on pasture used the same year were all associated with the number of MAP-positive ES. These associations, as well as their biological plausibility and the results of other studies, provide evidence for the importance of hygiene and purchase precautions for the control of MAP on dairy farms.

\section{ACKNOWLEDGMENTS}

This project was funded by Alberta Milk (Edmonton, AB, Canada) and the Alberta Livestock and Meat Agency (ALMA; Edmonton, AB, Canada). We thank participating farmers and veterinarians for their involvement and John Kastelic (Department of Produc- 
tion Animal Health, University of Calgary, Calgary, $\mathrm{AB}$, Canada) for editing the manuscript.

\section{REFERENCES}

Ansari-Lari, M., M. Haghkhah, A. Bahramy, and A. M. N. Baheran. 2009. Risk factors for Mycobacterium avium subspecies paratuberculosis in Fars province (Southern Iran) dairy herds. Trop. Anim. Health Prod. 41:553-557.

Barkema, H. W., S. Hendrick, J. De Buck, G. G. Kaplan, and K. Rioux. 2010a. Crohn's disease in humans and Johne's disease in cattle - Linked diseases? Pages 197-213 in Zoonotic Pathogens in the Food Chain. D. Krause and S. Hendrick, ed. CAB International, Wallingford, UK.

Barkema, H. W., J. W. Hesselink, S. L. B. McKenna, A. Benedictus, and H. Groenendaal. 2010b. Global prevalence and economics of infection with Mycobacterium avium ssp. paratuberculosis in ruminants. Pages 10-21 in Paratuberculosis, Organism, Disease, Control. M. A. Behr and D. M. Collins, ed. CABI, Wallingford, UK.

Barkema, H. W., M. A. G. Keyserlingk, J. P. Kastelic, T. J. G. M. Lam, C. Luby, and J. P. Roy. 2015. Invited review: Changes in the dairy industry affecting dairy cattle health and welfare. J. Dairy Sci. 98:7426-7445. http://dx.doi.org/10.3168/jds.2015-9377.

Barkema, H. W., J. D. Van der Ploeg, Y. H. Schukken, T. J. G. M. Lam, G. Benedictus, and A. Brand. 1999. Management style and its association with bulk milk somatic cell count and incidence rate of clinical mastitis. J. Dairy Sci. 82:1655-1663.

Berghaus, R. D., J. E. Lombard, I. A. Gardner, and T. B. Farver. 2005. Factor analysis of a Johne's disease risk assessment questionnaire with evaluation of factor scores and a subset of original questions as predictors of observed clinical paratuberculosis. Prev. Vet. Med. 72:291-309.

Canadian Diary Information Centre. 2014. Dairy farming in Canada. Accessed Sept. 15, 2015. http://www.dairyinfo.gc.ca/index_e. php?s1=dff-fcil\&s2=farm-ferme\&s3=nb.

Collins, M. T., I. A. Gardner, F. B. Garry, A. J. Roussel, and S. J. Wells. 2006. Consensus recommendations on diagnostic testing for the detection of paratuberculosis in cattle in the United States. J. Am. Vet. Med. Assoc. 229:1912-1919.

Dohoo, I., M. Wayne, and S. Henrik. 2003. Validity in observational studies. Pages 207-234 in Veterinary Epidemiologic Research. M. S. McPike, ed. Atlantic Veterinary College, Charlottetown, PEI, Canada.

Dohoo, I. R., C. Ducrot, C. Fourichon, A. Donald, and D. Hurnik. 1997. An overview of techniques for dealing with large numbers of independent variables in epidemiologic studies. Prev. Vet. Med. 29:221-239.

Doré, E., J. Paré, G. Côté, S. Buczinski, O. Labrecque, J. P. Roy, and G. Fecteau. 2012. Risk factors associated with transmission of Mycobacterium avium ssp. paratuberculosis to calves within dairy herds: a systematic review. J. Vet. Intern. Med. 26:32-45.

Dziuban, C. D., and E. C. Shirkey. 1974. When is a correlation matrix appropriate for factor analysis. Psychol. Bull. 81:358-361.

Elliott, G. N., R. L. Hough, L. M. Avery, C. A. Maltin, and C. D. Campbell. 2015. Environmental risk factors in the incidence of Johne's disease. Crit. Rev. Microbiol. 41:488-507. http://dx.doi.or g/10.3109/1040841X.2013.867830.

Fecteau, M. E., and R. H. Whitlock. 2010. Paratuberculosis in cattle. Pages 144-156 in Paratuberculosis-Organism, Disease And Control. M. A. Behr and D. M. Collins, ed. CABI, Wallingford, UK.

Fecteau, M. E., R. H. Whitlock, C. D. Buergelt, and R. W. Sweeney. 2010. Exposure of young dairy cattle to Mycobacterium avium ssp. paratuberculosis (MAP) through intensive grazing of contaminated pastures in a herd positive for Johne's disease. Can. Vet. J. 51:198-200.

Forde, T., J. De Buck, B. Elkin, S. Kutz, F. van der Meer, and K. Orsel. 2013. Contrasting results of culture-dependent and molecular analyses of Mycobacterium avium ssp. paratuberculosis from wood bison. Appl. Environ. Microbiol. 79:4448-4454.
Greenland, S., J. Pearl, and J. M. Robins. 1999. Causal diagrams for epidemiologic research. Epidemiology 10:37-48.

Johnson, K., C. C. Burn, and C. C. Wathes. 2011. Rates and risk factors for contagious disease and mortality in young dairy heifers. Anim. Sci. Rev. XX:205-214.

Johnson-Ifearulundu, Y. J., and J. B. Kaneene. 1998. Managementrelated risk factors for $M$. paratuberculosis infection in Michigan, USA, dairy herds. Prev. Vet. Med. 37:41-54.

Johnson-Ifearulundu, Y., and J. B. Kaneene. 1999. Distribution and environmental risk factors for paratuberculosis in dairy cattle herds in Michigan. Am. J. Vet. Res. 60:589-596.

Lavers, C. J., S. L. B. McKenna, I. R. Dohoo, H. W. Barkema, and G. P. Keefe. 2013. Evaluation of environmental fecal culture for $M y$ cobacterium avium subspecies paratuberculosis detection in dairy herds and association with apparent within-herd prevalence. Can. Vet. J. 54:1053-1060.

McKenna, S. L. B., G. P. Keefe, A. Tiwari, J. A. VanLeeuwen, and H. W. Barkema. 2006. Johne's disease in Canada Part II: Disease impacts, risk factors and control programs for dairy producers. Can. Vet. J. 47:1089-1099.

Mortier, R. A. R., H. W. Barkema, J. M. Bystrom, O. Illanes, K. Orsel, R. Wolf, G. Atkins, and J. De Buck. 2013. Evaluation of age-dependent susceptibility in calves infected with two doses of Mycobacterium avium subspecies paratuberculosis using pathology and tissue culture. Vet. Res. 44:94.

Mortier, R. A. R., H. W. Barkema, K. Orsel, R. Wolf, and J. De Buck. 2014. Shedding patterns of dairy calves experimentally infected with Mycobacterium avium subspecies paratuberculosis. Vet. Res. 45:71-80.

Nielsen, S. S., H. Bjerre, and N. Toft. 2008. Colostrum and milk as risk factors for infection with Mycobacterium avium subspecies paratuberculosis in dairy cattle. J. Dairy Sci. 91:4610-4615.

Nielsen, S. S., and N. Toft. 2011. Effect of management practices on paratuberculosis prevalence in Danish dairy herds. J. Dairy Sci. 94:1849-1857.

Ott, S. L., S. J. Wells, and B. A. Wagner. 1999. Herd-level economic losses associated with Johne's disease on US dairy operations. Prev. Vet. Med. 40:179-192.

Pillars, R. B., D. L. Grooms, J. A. Woltanski, and E. Blair. 2009. Prevalence of Michigan dairy herds infected with Mycobacterium avium subspecies paratuberculosis as determined by environmental sampling. Prev. Vet. Med. 89:191-196.

Pithua, P., L. A. Espejo, S. M. Godden, and S. J. Wells. 2013. Is an individual calving pen better than a group calving pen for preventing transmission of Mycobacterium avium ssp. paratuberculosis in calves? Results from a field trial. Res. Vet. Sci. 95:398-404.

Ritter, C., R. Wolf, J. Flaig, C. Pickel, M. Slomp, B. S. Mason, D. Kelton, J. Jansen, J. De Buck, and H. W. Barkema. 2014. Participation in the Alberta Johne's Disease Initiative is not associated with MAP herd prevalence, herd size or enrolment in a DHI program. Page 112 in Proc. 12th Intern. Colloq. Paratuberculosis (ICP), Parma, Italy. International Association for Paratuberculosis, Parma, Italy.

Scott, H. M., O. Sorenson, J. T. Wu, E. Y. Chow, K. Manninen, and J. A. VanLeeuwen. 2006. Seroprevalence of Mycobacterium avium subspecies paratuberculosis, Neospora caninum, bovine leukemia virus, and bovine viral diarrhea virus infection among dairy cattle and herds in Alberta and agroecological risk factors associated with seropositivity. Can. Vet. J. 47:981-991.

Sieber, M., A. E. Freeman, and P. N. Hinz. 1987. Factor analysis for evaluating relationships between first lactation type scores and production data of holstein dairy cows. J. Dairy Sci. 70:1018-1026.

Sweeney, R. W. 2011. Pathogenesis of paratuberculosis. Vet. Clin. North Am. Food Anim. Pract. 27:537-546.

USDA. 2003. Handbook for Veterinarians and Dairy Producers. A guide for Johne's disease risk assessment and management plans for dairy herds. Accessed Aug. 3, 2015. http://www.nd.gov/ndda/ files/resource/DairyRiskAssessment1stYear2011_0.pdf.

van Roermund, H. J. W., D. Bakker, P. T. J. Willemsen, and M. C. M. de Jong. 2007. Horizontal transmission of Mycobacterium avium ssp. paratuberculosis in cattle in an experimental setting: 
Calves can transmit the infection to other calves. Vet. Microbiol. 122:270-279.

van Schaik, G., Y. H. Schukken, M. Nielen, A. A. Dijkhuizen, H. W. Barkema, and G. Benedictus. 2002. Probability of and risk factors for introduction of infectious diseases into Dutch SPF dairy farms: A cohort study. Prev. Vet. Med. 54:279-289.

Vary, P. H., P. R. Andersen, E. Green, J. Hermon-Taylor, and J. J. McFadden. 1990. Use of highly specific DNA probes and the polymerase chain reaction to detect Mycobacterium paratuberculosis in Johne's disease. J. Clin. Microbiol. 28:933-937.

Wells, S. J., and B. A. Wagner. 2000. Herd-level risk factors for infection with Mycobacterium paratuberculosis in US dairies and association between familiarity of the herd manager with the disease or prior diagnosis of the disease in that herd and use of preventive measures. J. Am. Vet. Med. Assoc. 216:1450-1457.

Whittington, R. J., D. J. Marshall, P. J. Nicholls, I. B. Marsh, and L. A. Reddacliff. 2004. Survival and dormancy of Mycobacterium avium ssp. paratuberculosis in the environment. Appl. Environ. Microbiol. 70:2989-3004.

Windsor, P. A., and R. J. Whittington. 2010. Evidence for age susceptibility of cattle to Johne's disease. Vet. J. 184:37-44.

Wolf, R., H. W. Barkema, J. De Buck, M. Slomp, J. Flaig, D. Haupstein, C. Pickel, and K. Orsel. 2014a. High herd-level prevalence of Mycobacterium avium subspecies paratuberculosis in Western Canadian dairy farms, based on environmental sampling. J. Dairy Sci. 97:6250-6259.

Wolf, R., F. Clement, H. W. Barkema, and K. Orsel. 2014b. Economic evaluation of participation in a voluntary Johne's disease prevention and control program from a farmer's perspective- The Alberta Johne's Disease Initiative. J. Dairy Sci. 97:2822-2834.

Wolf, R., K. Orsel, J. De Buck, and H. W. Barkema. 2015. Calves shedding Mycobacterium avium subspecies paratuberculosis are common on infected dairy farms. Vet. Res. 46:71-79.

\section{APPENDIX}

Table A1. Frequency of risk factors on farms participating in the Alberta Johne's Disease Initiative, stratified by the number of Mycobacterium avium ssp. paratuberculosis (MAP)-positive environmental samples

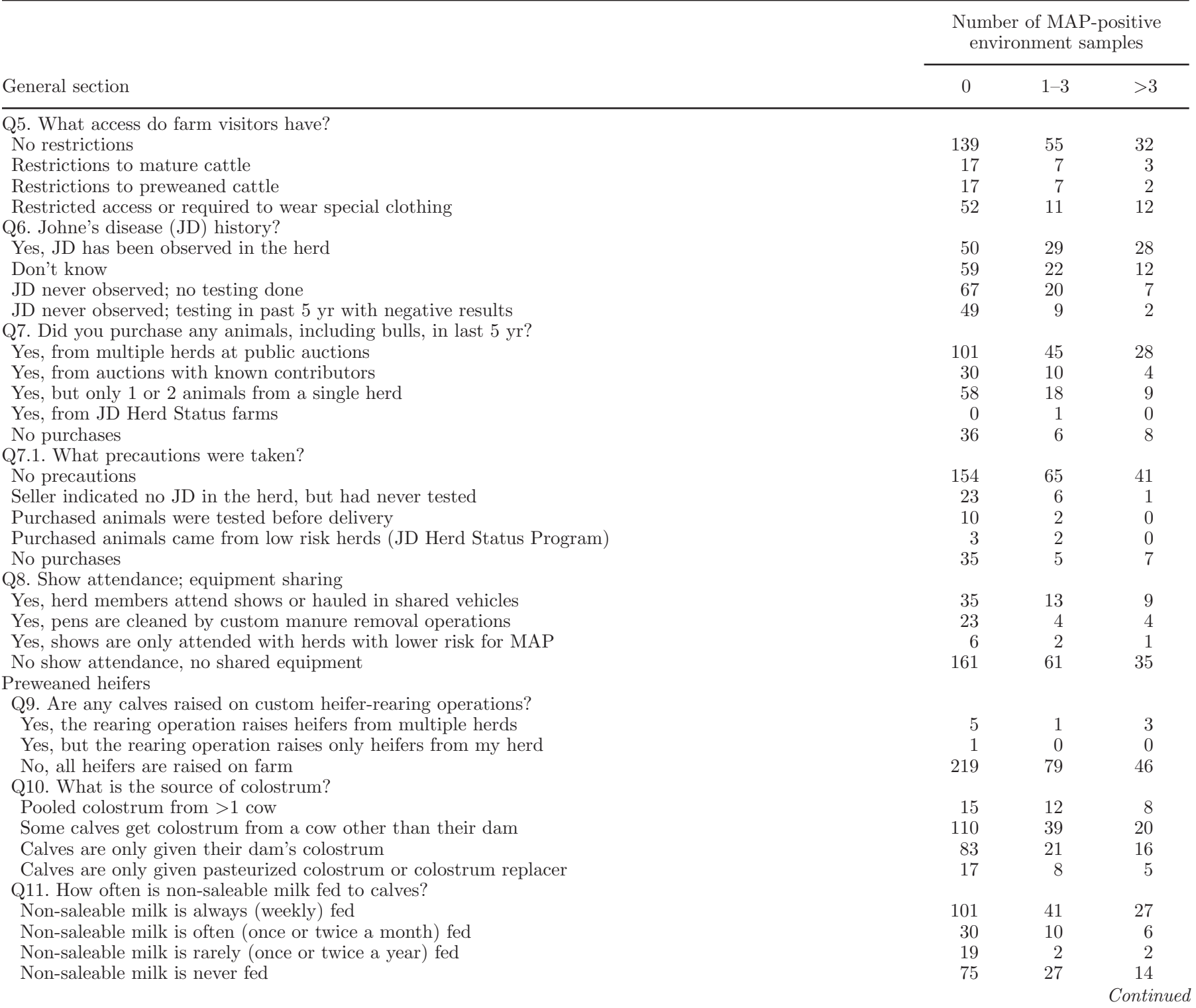


Table A1 (Continued). Frequency of risk factors on farms participating in the Alberta Johne's Disease Initiative, stratified by the number of Mycobacterium avium ssp. paratuberculosis (MAP)-positive environmental samples

Number of MAP-positive environment samples

Q12. What are the sources of liquid diet fed to calves?

Bulk or pooled milk

Milk from individual cows

Pasteurized milk or milk replacer for $<2$ yr

Pasteurized milk or milk replacer for $>2 \mathrm{yr}$

Q13. Is there any cow manure on milk feeding utensils?

Extensive manure contamination

Some manure contamination

Traces of manure, but utensils washed at least weekly

No manure, utensils washed daily

Q14. Is there any cow manure in water buckets and feed bunks?

Extensive manure contamination

Manure is clearly visible in calf feeders or water buckets

A scant amount of manure is visible

All calf feed and water containers are clean

Q15. How are calves housed?

Close proximity to cows

Group pens until weaning

Individual pens with contact through partitions

Individual pens without contact

Q16. Staff hygiene routine when entering calf barn

Staff never clean boots or change coveralls

Staff sometimes clean boots and change coveralls

Staff always clean boots and sometimes change coveralls

Staff always clean boots and change coveralls

Weaned heifers

Q17. Exposure to cow manure or runoff

Heifers share pens or pastures with cows

Heifers are housed near cows, exposure to runoff

Heifers housed near cows, no exposure to runoff

Heifers never housed near cows, no exposure to runoff

Q18. Manure contamination of feed bunks and water troughs

Manure build up in housing, contaminated feed bunks and water troughs

Manure clearly visible in feed bunks and water troughs

Traces of manure visible, feed bunks and water troughs cleaned more than once a month

No manure visible, feed bunks and water troughs cleaned more often than once a month

Q19. Is feed equipment used for manure, or left over feed given to heifers?

Feeding equipment is used to remove manure

Feeding equipment not used for manure, but cow left over feed fed to heifers $<1$ yr of age

Feeding equipment not used for manure, but cow left over feed fed to heifers $>1$ yr of age

Feeding equipment is not used for manure, left over feed is never fed to heifers

Q20. To what degree is manure contamination evident on heifers?

Manure is present above hocks/knees and on flanks

Manure is present on hocks/knees or on flanks

Manure is present up to dewclaws

No visible manure on animals

Q21. Manure spread on heifer forage or pasture used the same year

Manure is spread on pastures where heifers graze

Manure is spread on land next to heifer pastures

Manure is spread on forage land used to feed heifers

Manure is never spread on land used for heifers

Calving pen

Q22. How many cows are in a calving pen at a time?

$>1$ cow $>50 \%$ of the time

$>1$ cow $25-50 \%$ of the time

$>1$ cow $<25 \%$ of the time

Never $>1$ cow

Q23. How contaminated with manure is the calving pen?

Visible manure covering $>2 / 3$ of the bedding

Visible manure covering $50 \%$ of the bedding

Visible manure covering $10 \%$ of the bedding

No visible manure
129

27

19

$45-25$

8

66

151

7

49

169

8
40
71

71

106

$\begin{array}{rr}5 & 25 \\ 10 & 7\end{array}$

10

10

7

4

0

0

21

53

$\begin{array}{rrr}71 & 31 & 17 \\ 94 & 29 & 19 \\ 30 & 10 & 7 \\ 30 & 10 & 6 \\ & & \\ 6 & 3 & 5 \\ 61 & 21 & 11 \\ 94 & 38 & 23 \\ 64 & 18 & 9 \\ & & \\ 98 & 30 & 24 \\ 26 & 11 & 9 \\ 29 & 15 & 8 \\ 72 & 24 & 7\end{array}$


Table A1 (Continued). Frequency of risk factors on farms participating in the Alberta Johne's Disease Initiative, stratified by the number of Mycobacterium avium ssp. paratuberculosis (MAP)-positive environmental samples

Number of MAP-positive

environment samples

General section

$0 \quad 1-3 \quad>3$

Q24. To what degree is manure contamination evident on cows?

Manure present above hocks and on teats or udders

Manure present up to hocks or on teats or udders

Manure present above dewclaws, but not on teats or udders

No visible manure, udder hair is clipped and teats are washed

$6 \quad 220$

Q25. Use of calving area for sick cows

Frequent use of calving area by non-calving cows or known MAP positive cows

Occasional use of calving area by non-calving cows

Rare use of calving area by non-calving cows

Calving area is never used by non-calving cows

Q26. Calves born outside the calving area in the past year

$>10 \%$

$6-10 \%$

$1-5 \%$

Never

Q27. What percentage of calves nurse their dam?

$>50 \%$ nurse their dam, are left $>4 \mathrm{~h}$

$10-50 \%$ nurse their dam

$<10 \%$ nurse their dam

None

Q28. How long do calves stay with their dam?

$<10 \%$ of calves are removed $<30 \mathrm{~min}$

$10-50 \%$ are removed $<30 \mathrm{~min}$

$50-90 \%$ are removed $<30 \mathrm{~min}$

$>90 \%$ are removed $<30 \mathrm{~min}$

$\begin{array}{rrr}63 & 19 & 13 \\ 126 & 52 & 21 \\ 30 & 7 & 7 \\ & & \\ 43 & 17 & 14 \\ 46 & 11 & 10 \\ 69 & 25 & 9 \\ 67 & 27 & 16 \\ & & \\ 53 & 15 & 7 \\ 23 & 5 & 4 \\ 93 & 46 & 29 \\ 56 & 14 & 9 \\ & & \\ 53 & 19 & 15 \\ 64 & 17 & 14 \\ 94 & 36 & 17 \\ 14 & 8 & 3 \\ & & \\ 112 & 31 & 24 \\ 42 & 22 & 12 \\ 49 & 17 & 8 \\ 21 & 10 & 5\end{array}$

Dry cows

Q29. Manure contamination of feed bunks and water troughs

Extensive manure contamination

Manure clearly visible

Trace amounts of manure visible

No manure contamination

Q30. Manure contamination in dry cow forage or on pasture used the same year

Feeding equipment is used to scrape manure

Feeding equipment not used to scrape manure, but manure spread on pasture or crop land

Feeding equipment not used to scrape manure, manure not spread on pasture but on crop land

Feeding equipment not used to scrape manure, and manure not spread on pasture or crop land

Q31. Manure contamination on close up cows

Manure above knees/hocks and on flanks

Manure above knees/hocks but not on flanks

Manure not above knees/hocks

Cows are clean above fetlocks

Lactating cows

Q32. Manure contamination of feed bunks and water troughs

Extensive manure contamination

Manure clearly visible

Trace amounts of manure visible

No manure contamination

Q33. Manure contamination in lactating cows forage or on pasture used in the same year

Feeding equipment is used to scrape manure

Feeding equipment not used to scrape manure, but manure spread on pasture or crop land

Feeding equipment not used to scrape manure, manure not spread on pasture but on crop land

Feeding equipment not used to scrape manure, and manure not spread on pasture or crop land

Q34. Manure contamination on close up cows

Manure above knees/hocks and on flanks

Manure above knees/hocks but not on flanks

Manure not above knees/hocks

Cows are clean above fetlocks

$\begin{array}{rrr}2 & 0 & 3 \\ 44 & 15 & 12 \\ 111 & 42 & 26 \\ 68 & 23 & 8 \\ & & \\ 94 & 31 & 23 \\ 19 & 12 & 5 \\ 28 & 13 & 13 \\ 84 & 24 & 8 \\ & & \\ 17 & 4 & 3 \\ 41 & 14 & 11 \\ 119 & 42 & 26 \\ 48 & 20 & 9 \\ & & \\ & & \\ 4 & 1 & 5 \\ 32 & 7 & 13 \\ 114 & 49 & 26 \\ 75 & 23 & 5 \\ & & \\ 96 & 30 & 23 \\ 19 & 12 & 5 \\ 25 & 14 & 13 \\ 85 & 24 & 8 \\ & & \\ 18 & 9 & 9 \\ 41 & 15 & 10 \\ 129 & 48 & 27 \\ 37 & 8 & 3 \\ & & \end{array}$

